University of Louisville

ThinkIR: The University of Louisville's Institutional Repository

Faculty Scholarship

$7-2008$

Psychometric Properties of a Modified Version of a Worksite

Harassment Tool-Preliminary Findings

Hanan Al-Modallal

Lynne A. Hall

University of Louisville, lynne.hall@louisville.edu

Debra Anderson

Follow this and additional works at: https://ir.library.louisville.edu/faculty

Part of the Nursing Commons

Original Publication Information

Al-Modallal, H., Hall, L.A., \& Anderson, D.G. (2008). Psychometric properties of the modified version of a worksite harassment tool: Preliminary findings. AAOHN, 56(7), 309-316.

ThinkIR Citation

Al-Modallal, Hanan; Hall, Lynne A.; and Anderson, Debra, "Psychometric Properties of a Modified Version of a Worksite Harassment Tool-Preliminary Findings" (2008). Faculty Scholarship. 692.

https://ir.library.louisville.edu/faculty/692

This Article is brought to you for free and open access by ThinkIR: The University of Louisville's Institutional Repository. It has been accepted for inclusion in Faculty Scholarship by an authorized administrator of ThinkIR: The University of Louisville's Institutional Repository. For more information, please contact thinkir@louisville.edu. 


\title{
Psychometric Properties of a Modified Version of a Worksite Harassment Tool-Preliminary Findings
}

\author{
by Hanan Al-Modallal, RN, PhD, Lynne Hall, DrPH, and Debra Anderson, PhD, APRN, BC
}

\begin{abstract}
This study examined the psychometric properties of a modified version of a worksite harassment tool. Data were collected from 180 long-haul female drivers. Cronbach's alpha was used to assess internal consistency. Principal components analysis was used to investigate the tool's dimensionality, and correlation analysis was used to investigate construct validity. Cronbach's alpha for the tool was 0.88 . Principal components analysis indicated the presence of two factors. Two items were eliminated due to low factor loadings. Cronbach's alpha for the short version ( 7 items) was 0.86 . Higher abuse scores were associated with poorer health and greater levels of stress. The greater the level of abuse, the poorer the woman's ability to sleep. The 7-item version of the worksite harassment tool is valid and reliable, easy to understand, and written at a 7 th grade reading level.
\end{abstract}

I ntimate partner violence, a growing public health problem, has moved beyond the boundaries of the home. Intimate partner violence can follow the woman to work, resulting in workplace violence. Women can be harassed at work by an intimate partner over the telephone or in-person (Riger, Ahrens, \& Blickenstaff, 2000). In a sample

\section{ABOUT THE AUTHORS}

Dr. Al-Modallal will be Assistant Professor, College of Nursing, Hashemite University, Zarqa, Jordan, starting in September. Dr. Hall is Associate Dean for Research and Scholarship and Marcia A. Dake Professor of Nursing Science and Dr. Anderson is Associate Professor of Nursing, University of Kentucky, College of Nursing, Lexington, $K Y$.

Dr. Strasser is President, Partners in Business Health Solutions, Inc., Toledo, $\mathrm{OH}$; and Adjunct Assistant Professor, University of Michigan, School of Nursing, Occupational Health Nursing Program, Ann Arbor, MI. of 90 women, 80 (89\%) reported being harassed by an intimate partner at the workplace (McFarlane et al., 2000).

Consequences associated with intimate partner violence at the workplace manifest in many ways; intimate partner violence adversely affects women's performance and productivity at work because of their inability to concentrate or perform job tasks (Swanberg \& Macke, 2006; Swanberg, Macke, \& Logan, 2006), leads to lost workdays (Lloyd \& Taluc, 1999; Shepard \& Pence, 1988; Swanberg \& Macke), and can result in job loss (Swanberg et al.). Intimate partner violence at the workplace is also costly. Businesses pay the cost of lost workdays due to intimate partner violence. In 1995, intimate partner violence resulted in lost productivity costing \$727.8 million (U.S. Depart- ment of Health and Human Services, 2003). The devastating consequences of intimate partner violence can extend to homicide. Sixteen percent of female homicides at the workplace are committed by intimate partners (National Institute for Occupational Safety and Health [NIOSH], 2001).

The purpose of this study was to examine the psychometric properties of a modified version of a worksite harassment measure. Given the increase in intimate partner violence at the workplace, valid and reliable measures are needed to assess this phenomenon and thus estimate the scope of the problem. Measures with acceptable psychometric properties enhance disclosure of abuse. Such measures facilitate the identification of intimate partner violence and support the need for intimate partner violence prevention programs to eliminate this problem in the workplace.

\section{LITERATURE REVIEW}

Efforts to develop and revise measures of intimate partner violence in the workplace have not emphasized intimate partner violence in the workplace as a separate and unique type of intimate partner violence. Some measures include a few items assessing intimate partner violence or harassment of women at the workplace. For example, the Composite Abuse Scale (CAS) includes two (items 16 and 26) of 30 items that focus on female employees' experi- 
ences of intimate partner violence at the workplace (Hegarty, Sheehan, \& Schonfeld, 1999). These items tend to be superficial. They focus on whether female employees have been bothered by an intimate partner either over the telephone or in-person, as indicated by items 13, 54, and 57 of the Obsessive Relational Intrusion (ORI) Scale (Cupach \& Spitzberg, 2000). In addition, items may center on a partner preventing or trying to prevent the woman from going to work, as indicated by item 23 of the Abusive Behavior Inventory (ABI) Scale (Shepard \& Campbell, 1992).

Few instruments have been developed specifically to assess intimate partner violence at the workplace. The Work/School Abuse Scale (W/SAS) was developed to identify the extent to which intimate partner violence interferes with work. It includes 12 items on two subscales: the Restraint Tactics subscale and the Interference Tactics subscale. The instrument had acceptable internal consistency (Cronbach's alpha $=0.82)$ among a sample of 35 women residing in shelters (Riger et al., 2000). Validity was supported by significant correlations between the two subscales of the W/ SAS and the physical abuse subscale of the Conflict Tactics Scale (Riger et al.). However, the W/SAS lacks some abuse tactics that could be exhibited by an intimate partner (Swanberg et al., 2006). It also lacks the ability to identify the effect of abuse on women's work performance and the resulting consequences (Brush, 2002). The Work-Related Control, Abuse, and Sabotage Checklist (WORCASC) is another tool to measure workplace abuse by an intimate partner (Brush). Internal consistency of the instrument was 0.92 in a sample of 162 welfare recipients. Significant relationships between the instrument and other work-related outcomes such as "had to quit the job" and "ever filed a protective order" supported its validity (Brush).

Although the W/SAS and the WORCASC both demonstrate evidence of validity and reliability, they do not include items addressing the consequences of intimate partner violence for women's employment. These consequences could include, but are not limited to, lost productivity, lost workdays, and loss of job by either resigning or being terminated.

A congressional report issued by the U.S. General Accounting Office, Health, Education, and Human Services Division (1998), summarized various abuse tactics used by intimate partners against working women and addressed outcomes of intimate partner violence for women's employment. The report summarized the results of key research studies identifying the extent to which women were discouraged or prevented from working by an intimate partner. These abuse tactics and outcomes were categorized into seven themes: partners discouraged women from working; partners prevented them from working; partners harassed them at work in-person; women were late for work or left early because of abuse; women missed work because of abuse; women were reprimanded at work for behaviors related to abuse; and women lost their jobs as a result of abuse (U.S. General Accounting Office).

On the basis of these seven themes, McFarlane et al. (2000) developed an 8-item worksite harassment assessment tool. Seven of the eight questions were the exact themes presented in the congressional report. The eighth question, added by McFarlane et al. (2000), was "Has the abuser bothered you at work over the telephone?" Summary scores of the 8 -item measure range from 0 to 8 , with a higher score indicating more abuse tactics experienced by respondents. McFarlane et al. (2000) used the tool in a descriptive study involving 90 women, but did not report any psychometrics of the measure. Cronbach's alpha was 0.76 for the eight items among a sample of 150 women seeking protective orders against their intimate partners (McFarlane et al., 2004). No additional studies examining the psychometric properties of this measure of worksite harassment were identified.

In response to the crucial need for a reliable and valid assessment measure, a modified version of the McFarlane et al. (2000) tool was developed. It includes 9 yes-no items. Seven of the items are the exact themes presented in the congressional report with minor changes in wording for clarity. Two items have been added: a general question exploring whether the woman has ever been bothered by an intimate partner and a question regarding whether a spouse or an intimate partner has called the woman at work to bother her.

The purpose of this study was to examine the psychometric properties of the modified tool in a sample of female long-haul truck drivers. The specific aims of the study were to determine the prevalence of intimate partner violence in the workplace among female long-haul drivers and to examine the internal consistency and construct validity of the tool. The following hypotheses were tested to address construct validity: higher abuse scores are associated with poorer general health; higher abuse scores are associated with greater perceived stress; and the higher the abuse score, the poorer the woman's ability to sleep.

\section{METHODS \\ Design and Sample}

Data were collected in a large cross-sectional study of long-haul truck drivers. For this study, data from 180 female long-haul truck drivers were used to evaluate the psychometric properties of the modified version of the worksite harassment tool. Female truckers were targeted because the focus was on intimate partner violence experienced by women. Participants had to be at least 21 years old because this is the minimum age at which a truck driver can secure a commercial driver's license. The ability to read English was required to respond to a self-administered questionnaire. Women were recruited from four truck shows in Boston, Dallas, Louisville, and Las Vegas. In addition, women were recruited from four truck stops in Portland, Chicago, and Des Moines and from two sites in Kentucky. 


\section{Instrumentation}

The Modified Worksite Harassment Tool. In addition to gathering information about whether women have ever been discouraged or prevented from going to work and whether they have ever been harassed at work in-person or by phone, this tool also identifies possible consequences of intimate partner violence (e.g., being reprimanded at work). Based on the procedure for scoring the original questions (McFarlane et al., 2004), the modified 9-item tool was scored 1 for a "yes" response and 0 for a "no" response. Consequently, the total score for the instrument ranges from 0 to 9 , with a higher score indicating greater abuse. A score of 0 indicates that a woman is not a victim of intimate partner violence at the workplace.

Measures Used for Hypotheses Testing of Construct Validity. For testing construct validity of the modified tool, three physical and psychological health indicators were chosen because it was hypothesized they would correlate with abuse scores.

Global Self-Rated Health. The women were asked to describe their health in general as they perceived it using a single self-rated item. Responses were rated on a 5-point scale (i.e., 1 = excellent, 2 = very good, 3 = good, 4 = fair, and $5=$ poor). This measure is valid for health surveys (Manor, Matthews, \& Power, 2001) including the National Health Interview Survey in the United States (Krause \& Jay, 1994) and Canada (Cott, Gignac, \& Badley, 1999). The self-rated health item is used to measure physical health problems (Cott et al.; Okun \& George, 1984) and psychological health determinants (Cott et al.; Manor et al.). It was strongly associated with serious (e.g., cancer and epilepsy) and less serious (e.g., eczema and hay fever) health problems (Manor et al.).

Perceived Stress Scale (PSS). The PSS (Cohen, Kamarck, \& Mermelstein, 1983) measures perceived psychological stress among adults. Each item was rated on a 5-point scale (i.e., $0=$ never, $1=$ almost never, 2 = sometimes, 3 = fairly often, and
4 = very often). The final score is a sum of the 10 item scores after scorereversing the 4 positive items (items 4, 5, 7, and 8). Possible scores range from 0 to 40. The PSS was found to be reliable $($ Cronbach's alpha $=0.84$ ) in a sample of male and female college students (Cohen et al.). Validity of the measure was supported by significant correlations with depressive symptoms, physical symptoms, and use of health care services among two samples of college students (Cohen et al.). The mean perceived stress score among the participants in this study was $15.9(S D=7.0)$.

Sleeping Well. One item measured the ability of participants to sleep well. This item was one of several items designed by the researchers to investigate various health habits. The item was used to test construct validity, as the authors hypothesized that higher levels of abuse would be associated with greater sleep difficulties. Responses to the item ranged from 0 (never) to 4 (always), with a higher score indicating absence of sleeping problems.

\section{Procedure}

The study was approved by the University of Kentucky Medical Institutional Review Board. After giving informed consent, the truckers were asked to respond to a self-administered questionnaire. The research team answered any questions the participants raised during data collection. The difference between being bothered and being abused by an intimate partner was clarified. Bothering includes a partner contacting a female employee at work by telephone or in-person for no acceptable reason. Abuse was defined as physical, sexual, or psychological assault at home that affected women's work attendance, performance, and career stability.

\section{Data Analysis}

Descriptive statistics were used to calculate frequencies and percentages for the demographics of the study sample and the individual abuse tactics of the modified tool. Reliability was determined by Pearson's correlations among all the items to test for item homogeneity. Internal consistency was calculated using Cronbach's alpha. Validity testing was conducted using Pearson's correlation to examine the relationship between total abuse scores on the modified tool and perceived stress scores. Spearman's rho was used to calculate the correlation between total abuse scores and participants' reports of their general health and ability to sleep well.

Principal components analysis was used to identify dimensions of intimate partner violence at the workplace measured by the tool. Orthogonal (Varimax) rotation was used to identify more distinct factors. Based on an assessment of the eigenvalues, the screeplot, and factor loadings after performing principal components analysis, the number of factors was identified. Internal consistency for the 7-item tool, after deleting the two items that had low factor loadings, was calculated using Cronbach's alpha. Correlational analysis was used to investigate construct validity via hypotheses testing. Validity testing used Pearson's correlation between the total abuse score for the 7-item tool and participants' stress score and Spearman's rho between the total abuse score for the 7-item tool and participants' reports of their general health and sleep. Validity testing using the 7-item tool was restricted to abused women only $(n=70)$.

\section{RESULTS}

The mean age of the participants was 45.5 years $(S D=9.4)$. One hundred twenty-nine participants $(73 \%)$ were married and $170(96 \%)$ were White. More than half the women $(n=100,57 \%)$ had received postsecondary education. Table 1 summarizes the demographics of the women. A significant proportion $(n=141,93 \%)$ reported driving with an intimate partner or spouse. Only 11 women (7\%) indicated they drive with someone other than an intimate partner. Abuse scores among the participants ranged from 0 to $9(M=1.09, S D=$ $1.96) ; 104$ women $(60 \%)$ reported no abuse and $70(40 \%)$ reported at least one abuse tactic exhibited by an inti- 
Table 1

Demographics of the Study Sample $(N=180)$

\begin{tabular}{|c|c|c|}
\hline & $N$ & $\%$ \\
\hline \multicolumn{3}{|l|}{ Marital status $(n=176)$} \\
\hline Married & 129 & 73.3 \\
\hline Single & 14 & 8 \\
\hline Divorced or separated & 29 & 16.4 \\
\hline Widowed & 1 & 0.6 \\
\hline Other & 3 & 1.7 \\
\hline \multicolumn{3}{|l|}{ Ethnicity $(n=177)$} \\
\hline White & 170 & 96 \\
\hline African American & 2 & 1.1 \\
\hline Native American & 4 & 2.3 \\
\hline Other & 1 & 0.6 \\
\hline \multicolumn{3}{|l|}{$\begin{array}{l}\text { Highest level of educa- } \\
\text { tion }(n=176)\end{array}$} \\
\hline Less than 12 th grade & 14 & 8 \\
\hline $\begin{array}{l}\text { High school or general } \\
\text { equivalency diploma }\end{array}$ & 62 & 35 \\
\hline Beyond high school & 100 & 57 \\
\hline \multicolumn{3}{|l|}{$\begin{array}{l}\text { No. of children younger } \\
\text { than } 18 \text { traveling with } \\
\text { the woman }(n=174)\end{array}$} \\
\hline 0 & 155 & 89 \\
\hline 1 & 12 & 6.9 \\
\hline 2 & 5 & 2.9 \\
\hline 3 & 1 & 0.6 \\
\hline 4 & 1 & 0.6 \\
\hline \multicolumn{3}{|l|}{$\begin{array}{l}\text { Total household income } \\
\qquad(n=175)\end{array}$} \\
\hline$<\$ 35,000$ & 26 & 14.9 \\
\hline$\$ 35,001-\$ 55,000$ & 51 & 29.1 \\
\hline$\$ 55,001-\$ 75,000$ & 39 & 22.3 \\
\hline$\$ 75,001-\$ 100,000$ & 20 & 11.4 \\
\hline$>\$ 100,000$ & 39 & 22.3 \\
\hline
\end{tabular}

mate partner. Table 2 summarizes the percentages of women who experienced each abuse tactic.

Because the modified tool's items are dichotomous, the mean value for each item ranged from 0 to 1 (Table 2). For dichotomized items, the standard deviation associated with each item's mean is not a robust criterion for removal of items from a measure strong in magnitude, ranging from 0.28 to 0.75 . All correlations among the items were highly significant $(p<.0001)$.

Corrected item-total correlations (CITC) were moderate to strong. The weakest were for item 3 ("Has your spouse or intimate partner called you on the telephone and bothered you at work?") and item 8 ("Has your spouse or intimate partner ever discouraged you from working?") $(r=0.55)$. The strongest CITC was for item 4 ("Have you ever been late for work or left work early because of abuse by your spouse or intimate partner?") ( $r=$ 0.72). Cronbach's alphas, with stepwise item deletion (one at a time), ranged from 0.83 to 0.85 , providing further evidence of internal consistency. Table 2 presents the alpha coefficients for the tool if one item was removed each time.

As indicated, women were asked to respond to questions about their general health, perceived stress, and sleep. Construct validity of the modified tool was examined by testing the relationship between the abuse score and each outcome. Spearman correlation coefficients indicated that higher abuse scores were not associated with poorer self-rated health $(r=0.13, p=.07)$, but were related to poorer sleeping $(r=-0.33, p<.0001)$. Higher abuse scores were also correlated with more self-reported stress $(r=0.42, p<.0001)$. Two of the three hypotheses were supported, providing evidence for construct validity of the modified tool.

Based on the results of the principal components analysis of the nine items, two factors were retained. Orthogonal (Varimax) rotation was used to provide distinct factor loadings for each of the nine items of the tool. Items 4, 5, 6, and 7 loaded on Factor I with factor loadings ranging from 0.74 to 0.88 . Items 1,2 , and 3 loaded on Factor II with factor loadings ranging from 0.74 to 0.83 . Items 8 and 9 loaded on both factors. Therefore, they were not included as items in either factor. Based on the general themes addressed by the items in each factor, Factor I represented conse- 
Table 2

\section{Descriptive Statistics, Psychometric Properties, and Factor Matrix of the Modified Version of the Worksite Harassment Tool With Varimax Rotation of Two Factors $(N=180)$}

\begin{tabular}{|c|c|c|c|c|c|c|}
\hline Abuse Tactic & $\begin{array}{c}\% \\
\text { Responding } \\
\text { "Yes" }\end{array}$ & M & SD & $\begin{array}{l}\text { Cronbach's } \\
\text { Alpha }^{a}\end{array}$ & Factor $I^{b}$ & Factor II \\
\hline $\begin{array}{l}\text { 1. Have you been bothered by your } \\
\text { spouse or intimate partner? }\end{array}$ & 28 & 0.28 & 0.45 & 0.85 & 0.14 & $\underline{0.83}$ \\
\hline $\begin{array}{l}\text { 2. Has your spouse or intimate partner } \\
\text { ever come to your worksite and both- } \\
\text { ered you at work? }\end{array}$ & 15 & 0.15 & 0.36 & 0.84 & 0.21 & $\underline{0.78}$ \\
\hline $\begin{array}{l}\text { 3. Has your spouse or intimate partner } \\
\text { called you on the telephone and both- } \\
\text { ered you at work? }\end{array}$ & 21 & 0.21 & 0.40 & 0.85 & 0.19 & $\underline{0.74}$ \\
\hline $\begin{array}{l}\text { 4. Have you ever been late for work or } \\
\text { left work early because of abuse by } \\
\text { your spouse or intimate partner? }\end{array}$ & 9 & 0.09 & 0.29 & 0.83 & $\underline{0.74}$ & 0.41 \\
\hline $\begin{array}{l}\text { 5. Have you ever missed work because } \\
\text { of abuse by your spouse or intimate } \\
\text { partner? }\end{array}$ & 7 & 0.07 & 0.25 & 0.84 & $\underline{0.88}$ & 0.16 \\
\hline $\begin{array}{l}\text { 6. Have you ever gotten into trouble at } \\
\text { work related to reasons caused by } \\
\text { abuse from your spouse or intimate } \\
\text { partner? }\end{array}$ & 4 & 0.04 & 0.20 & 0.85 & $\underline{0.84}$ & 0.16 \\
\hline $\begin{array}{l}\text { 7. Have you lost a job because of } \\
\text { abuse from your spouse or intimate } \\
\text { partner? }\end{array}$ & 4 & 0.04 & 0.20 & 0.84 & $\underline{0.88}$ & 0.18 \\
\hline $\begin{array}{l}\text { 8. Has your spouse or intimate partner } \\
\text { ever discouraged you from working? }\end{array}$ & 15 & 0.15 & 0.36 & 0.85 & $\underline{0.43}$ & $\underline{0.50}$ \\
\hline $\begin{array}{l}\text { 9. Has your spouse or intimate partner } \\
\text { ever prevented you from working? }\end{array}$ & 7 & 0.07 & 0.25 & 0.84 & $\underline{0.59}$ & $\underline{0.48}$ \\
\hline
\end{tabular}

quences of intimate partner violence on women's employment. Factor II represented abusive and bothering tactics used by intimate partners on women. Table 2 presents factor loadings for the nine items.

Reliability for the 7-item tool was calculated after deleting items 8 and 9 . Cronbach's alpha was 0.86. Correlations among the seven items ranged from 0.38 to 0.75 . All correlations were significant $(p<.0001)$. CITCs ranged from 0.55 to 0.69 . Cronbach's alphas for the 7-item tool, if one item at a time was removed, ranged from 0.79 to 0.81 . Table 3 displays the psychometric properties of the 7-item tool.
Descriptive statistics for the resulting seven items within the two factors were calculated after items 8 and 9 were deleted due to low factor loadings. The total abuse score measured by the 7-item tool ranged from 0 to $7(M=0.87, S D=1.57)$. The mean abuse score measured by Factor I was $0.24(S D=0.81)$. The mean abuse score measured by Factor II was $0.63(S D=1)$. Cronbach's alpha was 0.90 for Factor I and 0.77 for Factor II. The correlation between the two factors was 0.48 ( $p<$ .0001). The correlations among the four items on Factor I were moderate to strong. The weakest correlation was between items 4 and $6(r=0.59$, $p<.0001)$, and the strongest correlation was between items 6 and $7(r=$ $0.76, p<.0001)$. The correlation coefficients among the three items on Factor II ranged from 0.46 to 0.60 . All correlations between the items within both factors were significant $(p<.0001)$. CITCs of the items on each factor remained moderate to strong. Cronbach's alphas for Factor I, if one item at a time was removed, ranged from 0.83 to 0.88 . Cronbach's alphas for Factor II, if one item at a time was removed, ranged from 0.63 to 0.74 . Table 3 presents the psychometric properties of the 7- 
Table 3

\section{Psychometric Properties for the 7-Item Version of the Worksite Harassment Tool and the Two Factors Within the Tool}

\begin{tabular}{lcccc}
\hline $\begin{array}{l}\text { Abuse Tactic } \\
\text { 1. Have you been bothered by your spouse or } \\
\text { intimate partner? }\end{array}$ & CITC & $\begin{array}{c}\text { Cronbach's } \\
\text { Alpha }\end{array}$ & $\begin{array}{c}\text { CITC } \\
\text { (Factor I) }\end{array}$ & $\begin{array}{c}\text { CITC } \\
\text { (Factor II) }\end{array}$ \\
$\begin{array}{l}\text { 2. Has your spouse or intimate partner ever } \\
\text { come to your worksite and bothered you at } \\
\text { work? }\end{array}$ & 0.58 & 0.81 & 0.64 \\
$\begin{array}{l}\text { 3. Has your spouse or intimate partner called } \\
\text { you on the telephone and bothered you at } \\
\text { work? }\end{array}$ & 0.55 & 0.80 & 0.62 \\
$\begin{array}{l}\text { 4. Have you been late for work or left work } \\
\text { early because of abuse by your spouse or } \\
\text { intimate partner? }\end{array}$ & 0.69 & 0.81 & 0.54 \\
$\begin{array}{l}\text { 5. Have you ever missed work because of } \\
\text { abuse by your spouse or intimate partner? }\end{array}$ & 0.61 & 0.80 & 0.81 & \\
$\begin{array}{l}\text { 6. Have you gotten into trouble at work related } \\
\text { to reasons caused by abuse from your } \\
\text { spouse or intimate partner? }\end{array}$ & 0.61 & 0.81 & 0.75 & \\
$\begin{array}{l}\text { 7. Have you lost a job because of abuse from } \\
\text { your spouse or intimate partner? }\end{array}$ & 0.64 & 0.80 & 0.81 & \\
\hline $\begin{array}{l}\text { Note. ClTC = corrected item-total correlation. } \\
\text { alf item is removed from the scale. }\end{array}$ & & & \\
\hline
\end{tabular}

item tool as well as the two factors of the tool.

Further analysis was conducted to identify the relationship between the selected physical and psychological health indicators and the abuse score using the 7-item tool among abused women only. This analysis was conducted to examine whether the significant association among abused women using the 7-item tool would hold. An inverse association existed between abuse scores and the women's ratings of general health and a positive relationship existed between abuse scores and feelings of stress. Abuse scores were negatively associated with sleeping well. Table 4 displays the findings using the modified tool and the 7-item tool.

\section{DISCUSSION}

Findings provided support for the internal consistency of the modified worksite harassment tool. An alpha coefficient of 0.88 provided adequate evidence of item homogeneity. Coefficient alpha tends to increase as the number of items on a scale increases (Cortina, 1993), so an alpha coefficient of 0.88 for a scale containing 9 dichotomous items indicates acceptable reliability. The validity of this measure was supported by a significant association between the abuse score and other selected physical and psychological health indicators and the high reliability estimate for the modified tool. Principal components analysis indicated the presence of two factors: one identifying consequences of intimate partner violence for women's employment and one addressing abuse and bothering tactics used by an intimate partner. A moderate correlation between the two factors $(r=0.48, p<.0001)$ indicated that they measure two different dimensions within the construct of intimate partner violence.

The 7-item tool was valid and re- liable. The alpha coefficient of 0.86 is a robust indicator of its internal consistency. A tool that addresses abusive tactics used by an intimate partner and work-related consequences of abuse in seven items is a practical measure. The 7-item tool has a 7th grade reading level and is short. One idea is addressed per item. Four to 5 minutes are needed to complete the tool.

The significant associations between the abuse score as indicated by the 7-item tool and various physical and psychological health indicators (e.g., general health, feelings of stress, and sleeping well) provided further evidence of the obvious impact of intimate partner violence on many aspects of a woman's life, including her job. This association expands the conceptualization and understanding of intimate partner violence as an influential construct on a woman's social and professional life. 
Sometimes, measures of intimate partner violence do not specify the perpetrator. For example, the Abuse Assessment Screen (Soeken, McFarlane, Parker, \& Lominack, 1998) includes items asking a woman whether she has ever been physically or sexually abused. If a woman indicates abuse, she will be asked to identify the abuser. The perpetrator could be an intimate partner. The same measure of intimate partner violence can be used to identify abuse inflicted by various perpetrators. For example, the Conflict Tactics Scale can be used to address abuse inflicted by various perpetrators (Straus, 1979). The same abuse tactics can be used by a male intimate partner or a female intimate partner, a sibling, or a parent (Straus). With the 7-item tool, the abuser is identified as the spouse or intimate partner. In addition, the 7-item tool includes only the most common abuse tactics used by an abusive partner at the workplace.

Abuse tactics used by an intimate partner on a woman vary based on the circumstances surrounding the abuse. For example, choking is common during pregnancy (Bullock, Bloom, Davis, Kilburn, \& Curry, 2006). Therefore, all possible abuse tactics expected to be used on a woman in a particular situation need to be addressed within a measure. In addition, screening tools for intimate partner violence need to provide women the opportunity to disclose abuse. Screening tools should assess for the circumstances associated with specific types of abuse so that abused women can receive treatment, counseling, and referrals. Based on the findings of this study and the characteristics of the tool (i.e., brevity, readability, and the dimensions addressed), the 7-item tool meets these criteria.

Finally, the 7-item tool provides health professionals, social workers, and personnel responsible for on-thejob employee safety an opportunity to ask women about their experiences of intimate partner violence. Items do not stigmatize or invade a woman's privacy, but instead provide examples of possible job-related consequences of intimate partner violence.

\begin{tabular}{|c|c|c|}
\hline \multicolumn{3}{|c|}{$\begin{array}{c}\text { Table } 4 \\
\text { Correlations Between the Two Versions of the } \\
\text { Worksite Harassment Tool and the Selected Physical } \\
\text { and Psychological Health Indicators }\end{array}$} \\
\hline Health Indicator & $\begin{array}{c}\text { 9-Item Version } \\
(\mathrm{N}=180)\end{array}$ & $\begin{array}{c}\text { 7-Item Version } \\
(\mathrm{N}=70)\end{array}$ \\
\hline Global self-rated health & 0.13 & $0.15^{\star}$ \\
\hline Perceived stress & $0.42^{\star \star}$ & $0.41^{\star \star}$ \\
\hline Sleeping well & $-0.33^{\star *}$ & $-0.35^{\star *}$ \\
\hline
\end{tabular}

Along with various abuse tactics that could be used by an intimate partner, work-related consequences of intimate partner violence addressed by the 7-item tool provide unity to this scale. This unity provides a better conceptualization of intimate partner violence.

\section{IMPLICATIONS AND RECOMMENDATIONS}

Violence inflicted by humans has become a significant source of danger and threat to women at the workplace (Howard, 1996). Homicide is the primary cause of death among women in the workplace (NIOSH, 1997). Women are also vulnerable to being murdered by an intimate partner at the workplace (NIOSH, 2001). This threat could be even more serious in the trucking industry, as women often share the job with their partner. Ninety-three percent of the women in this study drive with an intimate partner or spouse.

In addition, the participants of this study are commercial drivers. They drive most of the time and are away from their home and family. Thus, couples who drive together have long contact times and almost no time away from each other. They share familial and job concerns. Disagreements are highly probable and could escalate the potential for various abuse tactics toward women. This may explain the high prevalence of abuse in this group (40\%). All working women need to be assessed for abuse. The 7-item tool is appropriate for this purpose.
As indicated by the findings of this study, the 7-item tool is easy to use. Occupational health nurses can use it in almost all workplaces. The tool can be used as part of the application process to screen newly hired women for abuse. Counseling can be offered if abuse is identified. Occupational health nurses can perform periodic screening for intimate partner violence to identify those experiencing it. Educational programs and referral services can be provided to victims of intimate partner violence once they are identified.

The 7-item tool can also be used as a proxy for lost productivity. It provides information about missed workdays and job loss resulting from intimate partner violence. Occupational health nurses in various work settings can provide a cost estimate of intimate partner violence specific to certain occupations by multiplying the average daily wage by the number of lost workdays for each victim of intimate partner violence. A cumulative estimate of the cost of intimate partner violence representing a specific type of industry or a specific industry in a specific geographical area can be provided. Community resources can then be directed to the occupations with the most vulnerable women.

Future studies examining the psychometric properties of the modified tool and the 7-item tool should include women with diverse characteristics from different settings, including retail stores and restaurants. A high percentage of women in this 


\title{
IN SUMMARY
}

\section{Psychometric Properties of a Modified Version of a Worksite Harassment Tool}

\author{
Preliminary Findings \\ Al-Modallal, H., Hall, L., \& Anderson, D. \\ AAOHN Journal 2008; 56(7), 309-316.
}

1

Intimate partner violence has moved beyond the boundaries of the home, often following women to work and affecting their performance and productivity.

2 The 7-item version of the worksite harassment tool is valid and reliable, easy to use, and written at a 7 th grade reading level.

3 Measures with acceptable psychometric properties enhance disclosure of abuse, facilitating the identification of abuse and supporting the need for abuse prevention programs.

study indicated that they drive with their intimate partner. Although the findings regarding the reliability and validity of the two tools were significant, driving with an intimate partner could be a reason for possible overestimation of the prevalence of abuse. Sharing a job with an intimate partner could mix personal and private issues with job issues. This mixture could increase the prevalence of abuse, which, in turn, could impact the consequences of abuse for a woman's employment. As a result, the psychometric properties of the modified tool and the 7-item tool could have been impacted.

This study was funded by Grant \#1R01 OH07931 awarded to Drs. Debra Anderson, Deborah Reed, and Steven Browning by the National Institute for Occupational Safety and Health (NIOSH), Centers for Disease Control and Prevention.

\section{REFERENCES}

Brush, L. D. (2002). Work-related abuse: A replication, new items, and persistent questions. Violence and Victims, 17(6), 743-757.

Bullock, L., Bloom, T., Davis, J., Kilburn, E., \& Curry, M. A. (2006). Abuse disclosure in privately and Medicaid-funded pregnant women. Journal of Midwifery and Women's Health, 51(5), 361-369.

Cohen, S., Kamarck, T., \& Mermelstein, R.
(1983). A global measure of perceived stress. Journal of Health and Social Behavior, 24(4), 385-396.

Cortina, J. M. (1993). What is coefficient alpha? An examination of theory and applications. Journal of Applied Psychology, 78(1), 98-104.

Cott, C. A., Gignac, M. A., \& Badley, E. M. (1999). Determinants of self rated health for Canadians with chronic disease and disability. Journal of Epidemiology and Community Health, 53(11), 731-736.

Cupach, W. R., \& Spitzberg, B. H. (2000). Obsessive relational intrusion: Incidence, perceived severity, and coping. Violence and Victims, 15(4), 357-372.

Hegarty, K., Sheehan, M., \& Schonfeld, C. (1999). A multidimensional definition of partner abuse: Development and preliminary validation of the Composite Abuse Scale. Journal of Family Violence, 14(4), 399-415.

Howard, J. (1996). State and local regulatory approaches to preventing workplace violence. Occupational Medicine, 11(2), 293-301.

Krause, N. M., \& Jay, G. M. (1994). What do global self-rated health items measure? Medical Care, 32(9), 930-942.

Lloyd, S., \& Taluc, N. (1999). The effects of male violence on female employment. Violence Against Women, 5(4), 370-392.

Manor, O., Matthews, S., \& Power, C. (2001). Self-rated health and limiting longstanding illness: Inter-relationships with morbidity in early adulthood. International Journal of Epidemiology, 30(3), 600-607.

McFarlane, J., Malecha, A., Gist, J., Schultz, P., Willson, P., \& Fredland, N. (2000). Indicators of intimate partner violence in women's employment: Implications for workplace action. AAOHN Journal, 48(5), 215-220

McFarlane, J., Malecha, A., Gist, J., Watson, K., Batten, E., Hall, I., et al. (2004). Protection orders and intimate partner violence: An 18-month study of 150 black, Hispanic, and white women. American Journal of Public Health, 94(4), 613-618.

National Institute for Occupational Safety and Health. (1997). NIOSH facts: Violence in the workplace. Retrieved September 17, 2001, from www.cdc.gov/niosh/violfs. html

National Institute for Occupational Safety and Health. (2001). Women's safety and health issues at work. Retrieved December 14 2007, from www.cdc.gov/niosh/01-123. html

Okun, M., \& George, L. (1984). Physician and self-ratings of health, neuroticism, and subjective well-being among men and women. Personality and Individual Differences, 5(5), 533-539.

Riger, S., Ahrens, C., \& Blickenstaff, A. (2000). Measuring interference with employment and education reported by women with abusive partners: Preliminary data. Violence and Victims, 15(2), 161-172.

Shepard, M., \& Pence, E. (1988). The effect of battering on the employment status of women. Affilia: Journal of Women and Social Work, 3(2), 55-61.

Shepard, M. F., \& Campbell, J. A. (1992). The Abusive Behavior Inventory: A measure of psychological and physical abuse. Journal of Interpersonal Violence, 7(3), 291-305.

Soeken, K. L., McFarlane, J., Parker, B., \& Lominack, M. C. (1998). The Abuse Assessment Screen: A clinical instrument to measure frequency, severity, and perpetrator of abuse against women. In J. C. Campbell (Ed.), Empowering survivors of abuse: Health care for battered women and their children (pp. 195-203). Thousand Oaks, CA: Sage Publications.

Straus, M. A. (1979). Measuring intrafamily conflict and violence: The Conflict Tactics Scales. Journal of Marriage and the Family, 41(1), 75-88.

Swanberg, J. E., \& Macke, C. (2006). Intimate partner violence and the workplace: Consequences and disclosure. Affilia: Journal of Women and Social Work, 21(4), 391406.

Swanberg, J. E., Macke, C., \& Logan, T. K. (2006). Intimate partner violence, women, and work: Coping on the job. Violence and Victims, 21(5), 561-578.

U.S. Department of Health and Human Services. (2003). Costs of intimate partner violence against women in the United States. Atlanta, GA: Centers for Disease Control and Prevention.

U.S. General Accounting Office. (1998). Domestics violence: Prevalence and implications for employment among welfare recipients (Publication No. 99-12). Washington, DC: Author. 